\title{
Interaction of Monosaccharides with Cobalt Tetrasulfophthalocyanine
}

\author{
Maria N. Malinkina, ${ }^{a}$ Anna S. Makarova, ${ }^{\text {b }}$ Sergei V. Makarov, ${ }^{a}$ \\ and Denis S. Salnikov
}

a Research Institute of Macroheterocyclic Compounds, Ivanovo State University of Chemistry and Technology, 153000 Ivanovo, Russia

' Institute of Solution Chemistry of RAS, 153045 Ivanovo, Russia

${ }^{\circledR}$ Corresponding authorE-mail: makarov@isuct.ru

The kinetics of reaction between monosaccharides and cobalt tetrasulfophthalocyanine was studied spectrophotometrically. The reaction is shown to proceed with measurable rates only in strongly alkaline solutions. A product of reaction is determined to be $\mathrm{Co}^{I}$ phthalocyanine $\left(\mathrm{Co}^{I}(\mathrm{TSP})^{5-}\right)$. The reducing ability of monosaccharides decreases in following sequence: $x y l o s e>$ fructose $>$ ribose > glucose. The main factor influencing on their reducing ability is shown to be ratio between furanose and open forms of monosaccharide. The results of this work allow to recommend using of monosaccharides in studies of reduced metal phthalocyanines and other tetrapyrrolic complexes. Indeed, to receive "pure" kinetics of their oxidation the reductant should not reduce oxidized complex again, i.e. redox cycle should not proceed. It is shown that this prerequisite is working in the case of glucose (reductant of Co ${ }^{I I}(T S P c)^{4-}$ ) and nitrite (oxidant of $\left.\mathrm{Co}^{I}\left(\mathrm{TSP}_{\mathrm{C}}\right)^{5-}\right)$. In contrast to reduction of $\mathrm{Co}^{I I}\left(\mathrm{TSPC}^{4-}\right.$ by glucose, oxidation of Co ${ }^{I}\left(T_{S P c}\right)^{5-}$ by nitrite proceeds in weakly alkaline and neutral solutions. Therefore the reverse process does not interfere with oxidation of $\operatorname{Co}^{I}\left(T_{S P C}\right)^{5-}$.

Keywords: Xylose, fructose, ribose, glucose, cobalt phthalocyanine, nitrite, kinetics, redox reactions.

\section{Взаимодействие моносахаридов с тетрасульфофталоцианином кобальта}

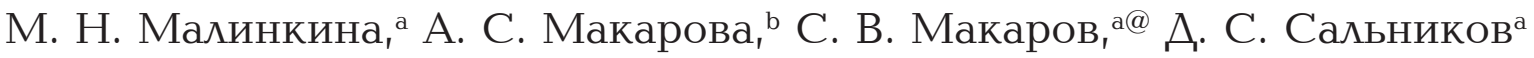 \\ а НИИ химии макрогетероциклических соединений, Ивановский государственный химико-технологический \\ университет, 153000 Иваново, Россия \\ ${ }^{\mathrm{b}}$ Институт химии растворов РАН, 153045 Иваново, Россия \\ @E-mail:makarov@isuct.ru
}

\begin{abstract}
Определены кинетические параметры реакиии тетрасульфофталоцианина кобальта с моносахаридами. Показано, что восстановление металлофталочианина протекает только в сильнощелочных средах. Установлена последовательность уменьшения восстановительной активности моносахаридов: ксилоза > фруктоза > рибоза > глюкоза. Показано, что фактором, определяющим восстановительную активность моносахаридов в водном растворе, является содержание фуранозной и открытой форм.
\end{abstract}

Ключевые слова: Ксилоза, фруктоза, рибоза, глюкоза, фталоцианин кобальта, нитрит, кинетика, окислительновосстановительные реакции.

\section{Введение}

Моносахариды являются важнейшими биологическими восстановителями. В последние годы существенно расширились области их применения в биохимии и химической технологии. Так, показано, что термическое восстановление нитрита моносахаридами может быть использовано при создании наносистем для контролируемого выделения NO. Этот способ обладает существенными преимуществами в сравнении с ранее известными методами. ${ }^{[1-3]}$ Применение моносахаридов для восстановления серосодержащих красителей является экономически и экологически выгодной альтернативой используемому сульфиду натрия. Восстанавливающие 
сахара дают сопоставимый, а во многих случаях более высокий выход красителя на волокно по сравнению с восстанавливающими агентами на основе сульфида, оказывающими негативное влияние на окружающую среду. Важно, что химическое потребление кислорода у всех сахаров ниже, чем у сульфида натрия. Кроме того, использование восстанавливающих сахаров приводит к значительной экономии воды. ${ }^{[4]}$

В настоящей работе исследовано взаимодействие моносахаридов с тетрасульфофталоцианином кобальта - эффективным катализатором многих практически важных процессов. ${ }^{[5-8]}$

\section{Экспериментальная часть}

В работе применялись следующие реагенты: глюкоза, рибоза, фруктоза, ксилоза (х.ч.); диоксид тиомочевины, дитионит натрия (Aldrich); тетрасульфофталоцианин кобальта был предоставлен проф. А. Сорокиным (Институт катализа, Виллербан, Франция) и использовался без предварительной очистки.

Кинетические эксперименты проводили в режиме термостатирования $\left( \pm 0.1^{\circ} \mathrm{C}\right)$ на спектрофотометре Specord M40 в бескислородных условиях (предварительно в течение 15 мин через растворы пропускали аргон). Полученные данные анализировали, используя программы Origin 7.5 и Mathcad.

Значения $\mathrm{pH}$ контролировали на $\mathrm{pH}$-метре мультитест ИПЛ-311 при помощи комбинированного стеклянного электрода ЭСК-10303/7 в цепи с переносом, градуированной по водным стандартным буферным растворам. Для поддержания заданного значения $\mathrm{pH}$ растворов применяли универсальную буферную смесь Бриттона-Робинсона.

Кинетику восстановления тетрасульфофталоцианина кобальта изучали путем измерения во времени оптической плотности на длине волны 450 нм, соответствующей восстановленной форме. Для определения величины $\varepsilon$ восстановленной формы комплекса проведены эксперименты с разныминачальнымиконцентрациямиСо ${ }^{\mathrm{II}}(\mathrm{TSP})^{4}$. Установлено, что закон Ламберта-Бугера-Бера выполняется до концентрации $3.3 \cdot 10^{-5}$ моль/л. Можно полагать, что в этом диапазоне и для $\mathrm{Co}^{\mathrm{I}}(\mathrm{TSPc})^{5-}$ будет выполняться закон Ламберта-Бугера-Бера. Показано, что при использовании в качестве восстановителя дитионита натрия и диоксида тиомочевины при одной и той же концентрации $\mathrm{Co}^{\mathrm{II}}(\mathrm{TSPc})^{4-}$ конечная оптическая плотность при 450 нм одинакова. Очевидно, в обоих случаях реакция восстановления протекает до конца, и конечная оптическая плотность на 450 нм отвечает концентрации $\mathrm{Co}^{\mathrm{I}}(\mathrm{TSPc})^{5-}$, равной исходной концентрации $\mathrm{Co}^{\mathrm{II}}(\mathrm{TSPc})^{4}$. На основании указанных данных рассчитывалось значение $\varepsilon_{450}$ для $\mathrm{Co}^{\mathrm{I}}(\mathrm{TSPc})^{5-}$. Кинетику реакции $\left(\mathrm{Co}^{\mathrm{I}}(\mathrm{TSPc})^{5-}\right)$ с нитритом изучали путем измерения оптической плотности на длине волны 450 нм.

\section{Обсуждение результатов}

Установлено, что при добавлении глюкозы к щелочному раствору тетрасульфофталоцианина кобальта в спектре поглощения появляется интенсивная полоса при 450 нм (Рисунок 1), одновременно наблюдается батохромный сдвиг $Q$-полосы. Цвет раствора меняется с синего на оливковый. Наличие изосбестической точки при 550 нм свидетельствует о присутствии в растворе двух форм. Конечный спектр, согласно литературным данным, соответствует поглощению $\mathrm{Co}^{\mathrm{I}}$ тетрасульфофталоцианина. ${ }^{[7]}$ Введение в раствор восстановленного комплекса кислорода приводит к образованию исходного комплекса $\mathrm{Co}^{\text {II. }}$. Аналогичные результаты имели место при использовании других углеводов - фруктозы, ксилозы, рибозы.

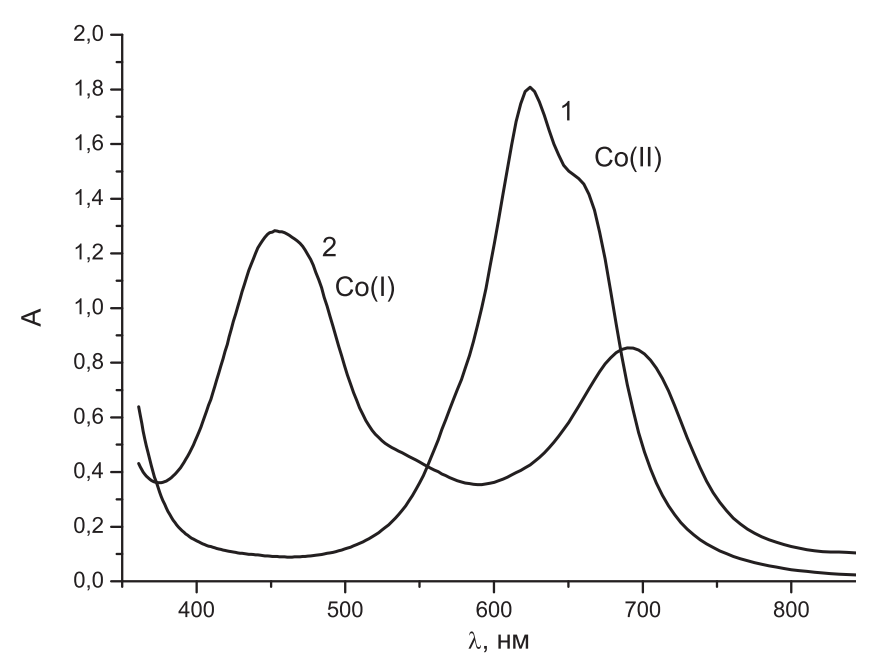

Рисунок 1. Исходный (1) и конечный (2) спектры, полученные при исследовании восттановления $\mathrm{Co}^{\mathrm{II}}(\mathrm{TSPc})^{4-}$ глюкозой; [глюкоза $]=0.1$ моль/л, $\left[\mathrm{Co}^{\text {II }}(\mathrm{TSPc})^{4-}\right]=3.0 \cdot 10^{-5}$ моль $/ л, 0.1$ моль/л $\mathrm{NaOH}, 298 \mathrm{~K}$.

Кинетику восстановления металлокомплексов исследовали в условиях реакции псевдопервого порядка при избытке углевода в отсутствие кислорода. На Рисунках 2 и 3 представлены кинетические кривые восстановления тетрасульфофталоцианина кобальта при различных значениях $\mathrm{p} H$ глюкозой и фруктозой соответственно. Аналогичные кривые получены при использовании в качестве восстановителя других моносахаридов - рибозы и ксилозы.

Поскольку в полулогарифмических координатах наблюдается линейная зависимость, можно полагать, что кинетика реакции описывается уравнением $\mathrm{r}=k_{\text {набл. }}$ $\left[\mathrm{Co}^{\mathrm{II}}(\mathrm{TSPc})^{4}\right]$. На основании экспериментальных данных рассчитаны наблюдаемые константы скорости реакции.

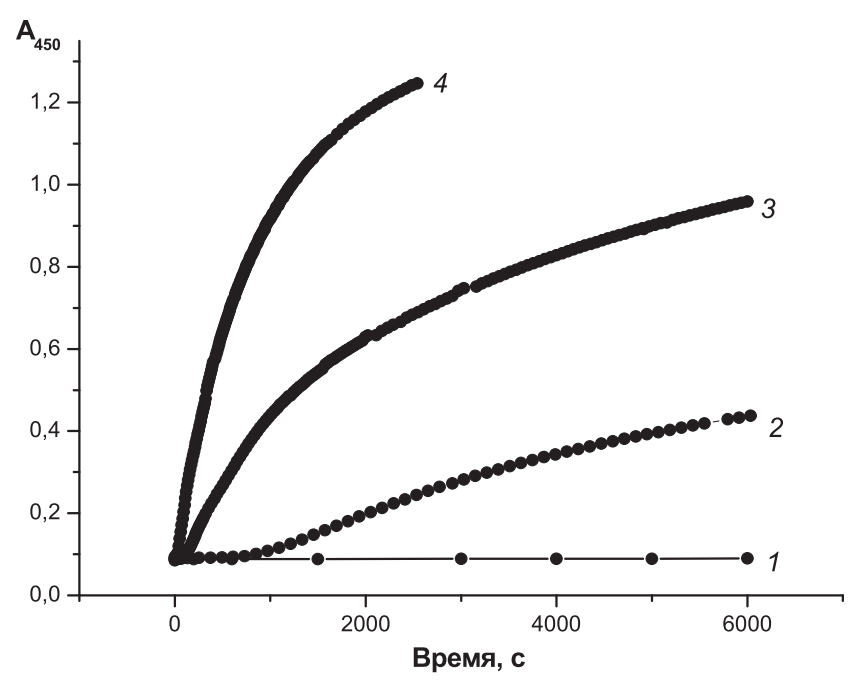

Рисунок 2. Изменение оптической плотности при 450 нм в процессе восстановления $\mathrm{Co}^{\mathrm{II}}(\mathrm{TSP})^{4-}$ глюкозой при $\mathrm{p} H$ 10.0 (1), 11.6 (2), 12.3 (3), 12.8 (4), [глюкоза] = 0.1 моль/л, $\left[\mathrm{Co}^{\mathrm{II}}(\mathrm{TSPc})^{4-}\right]=3.0 \cdot 10^{-5}$ моль $/ л, 298 \mathrm{~K}$. 
На Рисунке 4 представлены зависимости наблюдаемой константы скорости восстановления $\mathrm{Co}^{\mathrm{II}}(\mathrm{TSPc})^{4-}$ различными углеводами от $\mathrm{pH}$. Видно, что восстановление всеми углеводами протекает только в сильнощелочных средах. Так, при $\mathrm{p} H<11$ реакция не протекает, в диапазоне $\mathrm{p} H$ 11-12 скорость реакции невелика. При $\mathrm{pH}>12.8$ наблюдается резкий рост скорости восстановления комплекса. Установлено, что восстанавливающая способность углеводов по отношению к тетрасульфофталоцианину кобальта возрастает в ряду глюкоза $<$ рибоза $<$ фруктоза $<$ ксилоза. Похожий ряд активности моносахаридов в реакции с броминдиго, правда, при высокой температуре (80 $\left.{ }^{0} \mathrm{C}\right)$, был получен ранее ${ }^{[9]}$ - так же, как при восстановлении тетрасульфофталоцианина кобальта, наименее активна глюкоза, наиболее - ксилоза. Объяснение полученных зависимостей, однако, в работе ${ }^{[9]}$ отсутствует.

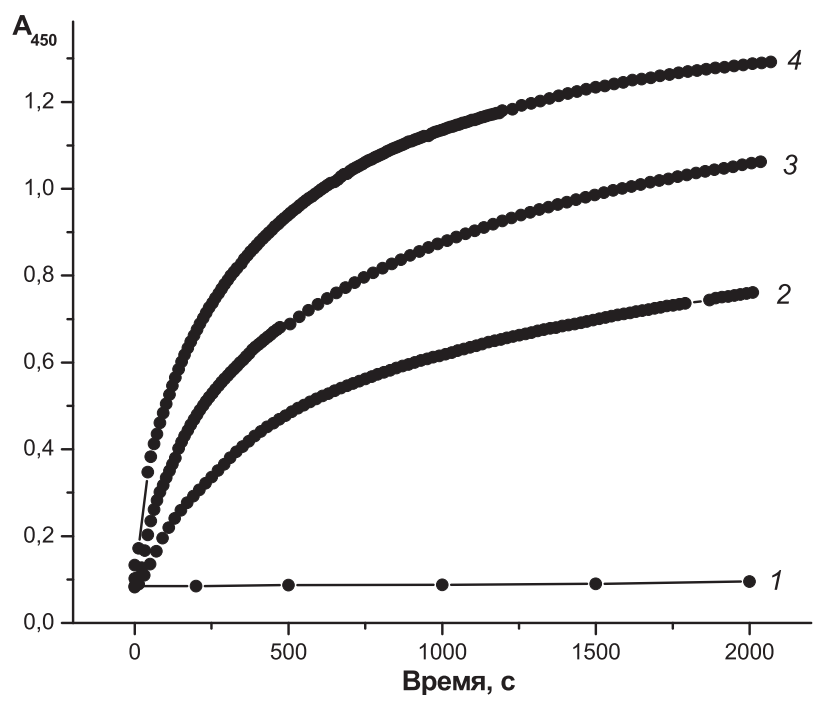

Рисунок 3. Изменение оптической плотности при 450 нм в процессе восстановления $\mathrm{Co}^{\mathrm{II}}(\mathrm{TSP})^{4-}$ фруктозой при $\mathrm{pH}$ 10.0 (1), 11.8 (2), 12.0 (3), 12.6 (4), [фруктоза] = 0.1 моль/л, $\left[\mathrm{Co}^{\mathrm{II}}(\mathrm{TSPc})^{4}\right]=3.0 \cdot 10^{-5}$ моль $/$ л, $298 \mathrm{~K}$.

Основной причиной различий в реакционной способности моносахаридов является, на наш взгляд, неодинаковое соотношение пиранозной, фуранозной и открытой форм в их водных растворах.

Известно, ${ }^{[10]}$ что пиранозная форма является значительно более стабильной формой моносахаридов, чем фуранозная (разница в свободных энергиях составляет $\sim 8$ кДж/моль). Следовательно, можно полагать, что при увеличении доли фуранозной и открытой форм в растворах реакционная способность моносахаридов в редокс реакциях будет возрастать. Это предположение подкрепляется данными о соотношении разных форм моносахаридов в

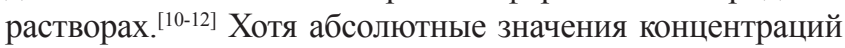
пиранозной, фуранозной и открытой форм моносахаридов, приведенные в разных источниках, отличаются, следует отметить, что концентрация фуранозной формы в растворах пентоз больше, чем в растворе глюкозы. Так, содержание фуранозной и открытой форм в глюкозе - наименьшее из всех моносахаридов, ${ }^{[10-12]}$ глюкоза является в то же время и наименее активной в редокс процессах. Содержание фуранозной формы в растворах фруктозы очень велико (около $30 \%$ при $30^{\circ} \mathrm{C}^{[10]}$ ) и превышает таковое в

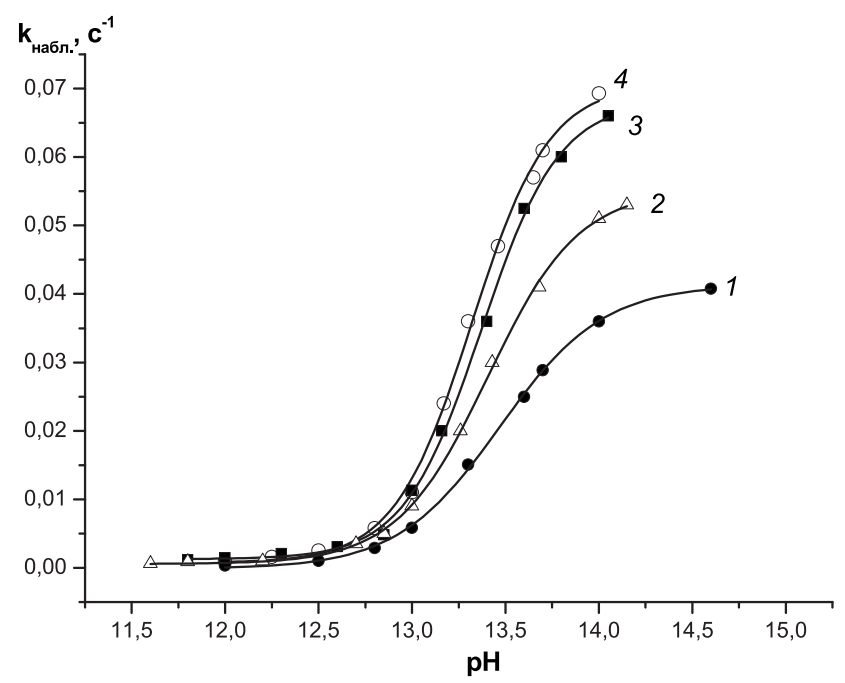

Рисунок 4. Зависимости наблюдаемой константы скорости восстановления $\mathrm{Co}^{\mathrm{II}}(\mathrm{TSP})^{4-}$ углеводами от $\mathrm{pH}$; глюкоза (1), рибоза (2), фруктоза (3), ксилоза (4), [углевод] $=0.1$ моль/л, $\left[\mathrm{Co}^{\mathrm{II}}(\mathrm{TSPc})^{4-}\right]=3.0 \cdot 10^{-5}$ моль $/ л, 298 \mathrm{~K}$.

случае рибозы и ксилозы. Содержание открытой формы в растворах фруктозы также велико $\left(0.7 \%\right.$ при $\left.30^{\circ} \mathrm{C}^{[10]}\right)$, однако, поскольку она является кетоформой, активность ее ниже, чем у открытых форм альдоз. Интересно, что в растворах галактозы - соединения, по строению очень мало отличающегося от глюкозы, содержание фуранозной и открытой форм значительно больше. ${ }^{[10,11]}$ Очевидно, этим объясняется существенно большая активность галактозы в редокс реакциях. ${ }^{[9]}$ Таким образом, реакционная способность моносахаридов в редокс процессах сложным образом зависит от их строения и, как следствие, содержания в растворе пиранозной, фуранозной и открытой форм, а также химической природы открытой формы.

На Рисунке 5 приведены примеры зависимостей наблюдаемой константы скорости восстановления $\mathrm{Co}^{\mathrm{II}}(\mathrm{TSP})^{4-}$ от концентрации углевода. Они нелинейны, но линеаризуются в координатах $1 / k_{\text {набл. }}-1 /[$ УГ] (где УГ

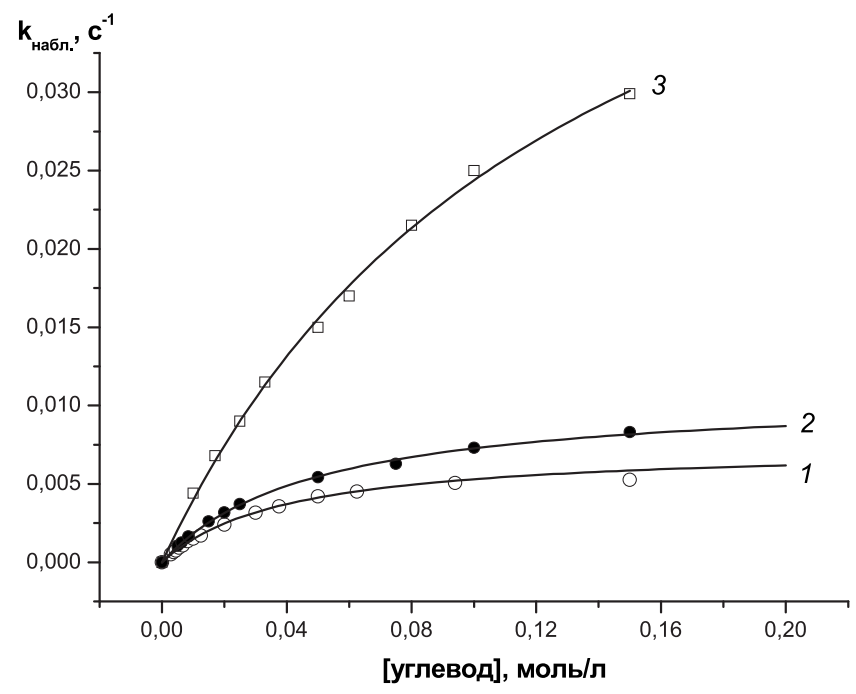

Рисунок 5. Зависимости наблюдаемой константы скорости восстановления $\mathrm{Co}^{\mathrm{II}}(\mathrm{TSPc})^{4-}$ от концентрации углевода; глюкоза (1), рибоза (2), фруктоза (3), $0.1 \mathrm{M} \mathrm{NaOH}$, $\left[\mathrm{Co}^{\mathrm{II}}(\mathrm{TSPc})^{4-}\right]=3.0 \cdot 10^{-5}$ моль/л, $298 \mathrm{~K}$. 
- углевод) во всем изученном интервале концентраций (Рисунок 6). Это характерно для реакций внутримолекулярного переноса электрона, которому предшествует быстрая реакция образования промежуточного комплекса тетрасульфофталоцианина и углевода. Наблюдаемая константа скорости реакции может быть описана следующим выражением ${ }^{[13]}$ :

$$
k_{\text {набл. }}=\frac{k K[У Г]}{1+K[У Г]} .
$$

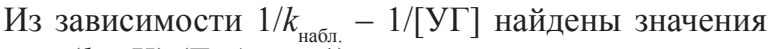
констант ( $k$ и K) (Таблица 1).

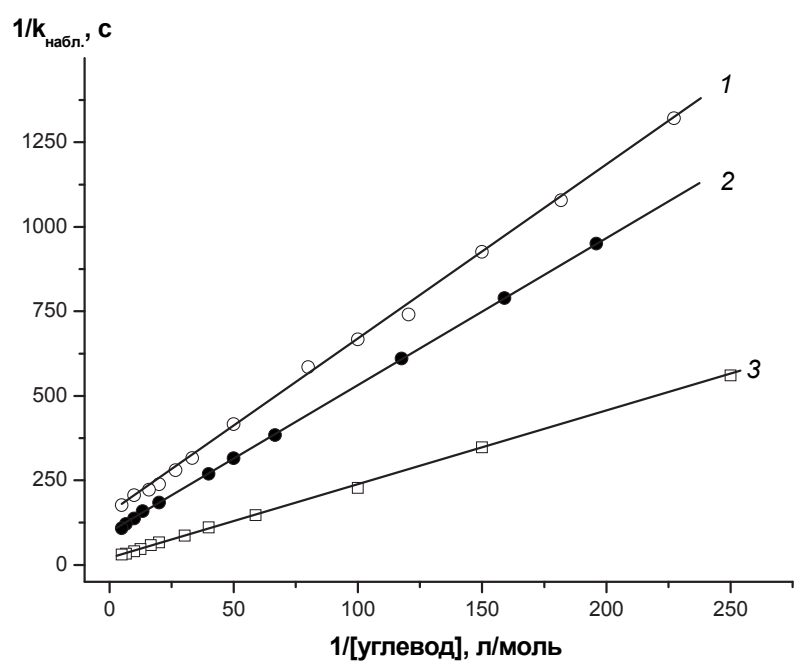

Рисунок 6. Зависимость $1 / k_{\text {набл. }}$ от $1 /[$ УГ], глюкоза (1), рибоза (2), фруктоза (3), $0.1 \mathrm{M} \mathrm{NaOH},\left[\mathrm{Co}^{\mathrm{II}}(\mathrm{TSPc})^{4-}\right]=3.0 \cdot 10^{-5}$ моль/л, 298 K.

Схему восстановления тетрасульфофталоцианина кобальта можно представить следующим образом:

$$
\begin{aligned}
& \text { K k } \\
& \mathrm{Co}^{\mathrm{II}}(\mathrm{TSPc})^{4-}+\mathrm{УГ} \leftrightarrows\left[\mathrm{Co}^{\mathrm{II}}(\mathrm{TSPc})^{4-} \mathrm{УГ}\right] \rightarrow \\
& \rightarrow \mathrm{Co}^{\mathrm{I}}(\mathrm{TSPc})^{5-}+\text { продукты окисления углеводорода }
\end{aligned}
$$

Кинетические и активационные параметры реакции восстановления тетрасульфофталоцианина кобальта углеводами представлены в Таблице 1. Из нее видно, что наименее активный моносахарид - глюкоза образует наиболее прочный промежуточный комплекс с тетрасульфофталоцианином кобальта. Промежуточным продуктом окисления моносахаридов является, по-видимому, радикал, который затем переходит в глюконовую и аналогичные (в случае других моноз) кислоты. Глюконовая кислота является продуктом окисления глюкозы, в частности, соединениями $\mathrm{Cu}^{\mathrm{II}}$. ${ }^{10]}$
Полученные в настоящей работе данные позволяют рекомендовать моносахариды для использования в качестве “вспомогательных" восстановителей при исследовании реакционной способности $\mathrm{Co}^{\mathrm{I}}(\mathrm{TSPc})^{5-}$. Свойства восстановленных форм фталоцианинов металлов изучены очень мало. Ранее нами были исследованы процессы восстановления нитрита серосодержащими восстановителями - дитионитом, ${ }^{[6]}$ гидроксиметансульфинатом натрия $^{[8]}$ и диоксидом тиомочевины (ДОТМ) ${ }^{[14]}$ в присутствии тетрасульфофталоцианина кобальта. Изучены отдельные стадии каталитического процесса - восстановление металлокомплекса и взаимодействие его восстановленной формы с нитритом. В настоящей работе определены константы скорости реакции $\mathrm{Co}^{\mathrm{I}}(\mathrm{TSPc})^{5-}$, полученного восстановлением $\mathrm{Co}^{\mathrm{II}}(\mathrm{TSPc})^{4-}$ глюкозой, с нитритом. На Рисунке 7 показана зависимость наблюдаемой константы скорости этой реакции от рН. Видно, что с ростом $\mathrm{p} H$ скорость окисления резко снижается, в сильнощелочной среде реакция практически не протекает. Наоборот, глюкоза восстанавливает тетрасульфофталоцианин кобальта только в сильнощелочных средах ( $\mathrm{pH}$ $>12$ ) (см. выше). Следовательно, осуществить каталитический цикл $\mathrm{Co}^{\mathrm{II}}-\mathrm{Co}^{\mathrm{I}}$ в системе глюкоза-СоTSPc-нитрит “в одном сосуде" не представляется возможным. Однако “разнонаправленность” влияния рН на скорость этих двух реакций дает возможность определить константы скорости процесса окисления $\mathrm{Co}^{\mathrm{I}}(\mathrm{TSPc})^{5-}$ нитритом в слабощелочных растворах. Проблема в случае других, в частности, указанных выше серосодержащих восстановителей

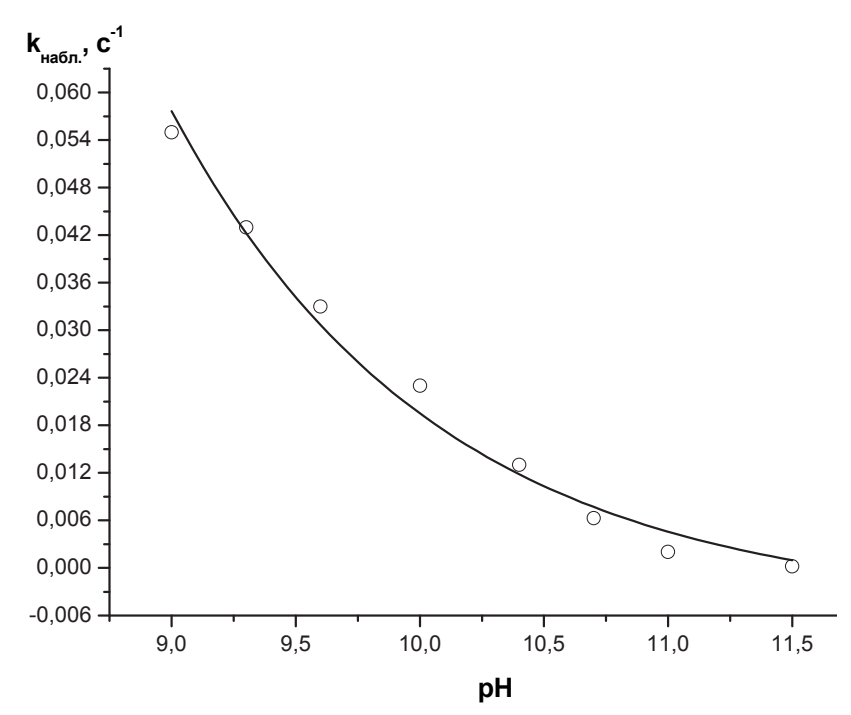

Рисунок 7. Зависимость наблюдаемой константы скорости окисления $\mathrm{Co}^{\mathrm{I}}(\mathrm{TSPc})^{5-}$ нитритом от $\mathrm{pH}$, [глюкоза] $=1 \cdot 10^{-3}$ моль/л, $\left[\mathrm{Co}(\mathrm{TSPc})^{5-}\right]=3.0 \cdot 10^{-5}$ моль/л, $\left[\mathrm{NaNO}_{2}\right]=0.1$ моль/л, $298 \mathrm{~K}$.

Таблица 1. Кинетические и активационные параметры реакции восстановления тетрасульфофталоцианина кобальта углеводами в $0.1 \mathrm{M} \mathrm{NaOH}$.

\begin{tabular}{ccccc}
\hline Углевод & $k, \mathrm{c}^{-1}$ & $\mathrm{~K}$, л/моль & $\Delta H^{\ddagger}$, кДж/моль & $\Delta S^{\ddagger}$, Дж/(моль·К) \\
\hline Глюкоза & $0.0072 \pm 0.0004$ & $26.26 \pm 0.84$ & $84 \pm 2$ & $-12 \pm 1$ \\
Рибоза & $0.0113 \pm 0.0006$ & $18.83 \pm 0.99$ & $74 \pm 3$ & $-43 \pm 2$ \\
Фруктоза & $0.054 \pm 0.0025$ & $8.12 \pm 0.45$ & $51 \pm 3$ & $-127 \pm 15$ \\
Ксилоза & $0.057 \pm 0.0028$ & $7.72 \pm 0.44$ & $54 \pm 4$ & $-119 \pm 20$ \\
\hline
\end{tabular}


Таблица 2. Наблюдаемые константы скорости реакции нитрита с $\mathrm{Co}^{\mathrm{I}}(\mathrm{TSPc})^{5-}$, полученного с использованием различных восстановителей; $\mathrm{pH} 10.0$, [восстановитель $]=1.0 \cdot 10^{-3}$ моль/л, $\left[\mathrm{NaNO}_{2}\right]=0.1$ моль/л, $\left[\mathrm{Co}^{\mathrm{I}}(\mathrm{TSPc})^{5-}\right]=3.0 \cdot 10^{-5}$ моль/л, $298 \mathrm{~K}$.

\begin{tabular}{ccccc}
\hline Восстановитель & ГМС & дитионит & ДОТМ & глюкоза \\
\hline$k_{\text {набл. }}, \mathrm{c}^{-1}$ & $0.033 \pm 0.003$ & $0.023 \pm 0.002$ & $0.0012 \pm 0.0001$ & $0.025 \pm 0.002$ \\
\hline
\end{tabular}

заключается в том, что, поскольку они взаимодействуют с $\mathrm{Co}^{\text {II }}(\mathrm{TSPc})^{4-}$ в широком интервале $\mathrm{pH}$, полностью исключить их влияние на реакцию $\mathrm{Co}^{\mathrm{I}}(\mathrm{TSPc})^{5-}$ с нитритом a priori нельзя (серосодержащие восстановители присутствуют в растворе при исследовании этой реакции!). Задачу устранения влияния восстановителя на кинетику реакций полученных с его помощью восстановленных форм комплексов решить весьма непросто. При исследовании реакций восстановленных форм кобаламинов для их получения используется амальгама цинка, ${ }^{[15,16]}$ т.е. реакция восстановления проводится в гетерогенных условиях при перемешивании, а стадия окисления является гомогенной, при этом перемешивание не используется. Полученные в настоящей работе результаты дают возможность рекомендовать другую методику, позволяющую изучить реакционную способность восстановленных форм металлофталоцианинов “в чистом виде": после полного восстановления комплекса глюкозой в 0.1 моль/л $\mathrm{NaOH}$ нужно подкислить раствор до $\mathrm{pH} 8-10$, а затем вводить нитрит.

Чтобы сравнить эффект различных восстановителей на кинетику окисления CoI (TSPc) $)^{5-}$ нитритом, в настоящей работе кинетика этой реакции изучена в одинаковых условиях. Важно отметить, что скорости реакции нитрита с $\mathrm{Co}^{\mathrm{I}}(\mathrm{TSPc})^{5-}$ в случаях, когда для его получения использовались глюкоза, гидроксиметансульфинат и дитионит натрия, практически одинаковы (Таблица 2). Следовательно, можно полагать, что во всех случаях окислению подвергается один и тот же комплекс, а присутствующий восстановитель или продукты его распада не влияют на реакцию окисления $\mathrm{Co}^{\mathrm{I}}(\mathrm{TSPc})^{5-}$. При использовании ДОТМ, однако, скорость окисления существенно ниже, что свидетельствует, очевидно, о влиянии продуктов разложения ДОТМ на реакцию окисления.

Таким образом, результаты настоящей работы свидетельствуют о возможности использования моносахаридов для получения Сo ${ }^{\mathrm{I}}(\mathrm{TSPc})^{5-}$ и исследования его реакционной способности в слабощелочных средах.
Благодарности. Работа выполнена при поддержке гранта РФФИ 11-03-00132а и гранта Президента Российской Федерации для молодых российских ученых - кандидатов наук МК-2618.2010-3.

\section{Список литературы}

\section{References}

1. Friedman A., Han G., Navati M.S., Chacko M., Gunther L., Alfieri A., Friedman J.M. Nitric Oxide 2006, 19, 12-20.

2. Navati M.S., Friedman J.M J. Phys. Chem. B 2010, 114, 29382943.

3. Makarov S.V. Priroda 2010, N 7, 34-37 (in Russ.).

4. Blackburn R.S., Harvey A. Environ. Sci. Technol. 2004, 38, 4034-4039.

5. Gregory P. J. Porphyrins Phthalocyanines 2000, 4, 432-437.

6. Kudrik E.V., Makarov S.V., Zahl A., van Eldik R. Inorg. Chem. 2003, 42, 618-624.

7. Kudrik E.V. Makarov S.V., Zahl A., van Eldik R. Inorg. Chem. 2005, 44, 6470 - 6475 .

8. Vlasova E.A., Makarova A.S., Makarov S.V., Ageeva E.S. Izv. Vyssh. Uchebn. Zaved., Khim. Khim. Tekhnol. 2010, 53, 75-79 (in Russ.).

9. Lepilova O.V. Dis. Cand. Scie. Techn. Ivanovo, 2007.

10. Advances in Carbohydrate Chemistry and Biochemistry (Tipson R.S., Horton D., Eds.) Vol. 42, Academic Press: London, 1984. $423 \mathrm{pp}$.

11. Paez M., Martinez-Castro I.., Sanz J., Olano A., Garcia-Raso A., Saura-Calixto F. Chromatographia 1987, 23, 43-46.

12. Pazur J.H., Misiel F.J., Liu B. J Chromatographia 1987, 396, 139-147.

13. Shmidt R., Sapunov V.N. Neformal'naya kinetika. V poiskakh putei khimicheskikh reaktsii [Nonformal Kinetics. In Finding Ways to Chemical Reactions]. Moskva: Mir, 1985. 264 p. (in Russ.).

14. Pogorelova A.S., Makarov S.V., Ageeva E.S., SilaghiDumitrescu R. Zh. Fiz. Khim. 2009, 83, 2250-2254 (in Russ.).

15. Balasubramanian P.N., Gould E.S. Inorg. Chem. 1983, 22, 26352637.

16. Wolak M., Zahl A, Schneppensieper T., Stochel G, van Eldik R J. Am. Chem. Soc. 2001, 123, 9780-9791. 